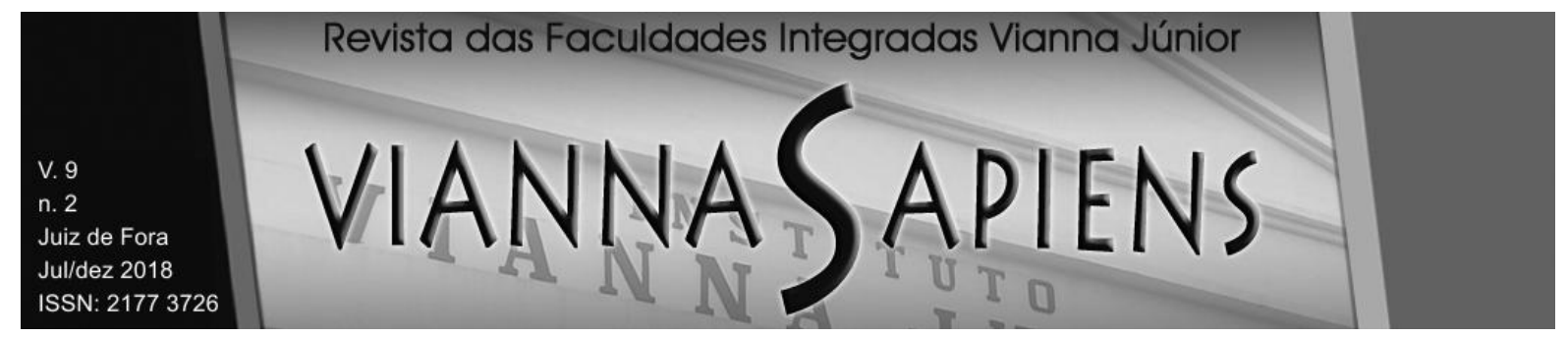

\title{
FATORES CRÍTICOS DE SUCESSO: ESTUDO DE CASO NA INCUBADORA DE EMPRESAS DE BASE TECNOLÓGICA DE UMA UNIVERSIDADE FEDERAL DO SUL DE MINAS GERAIS
}

DOI: 10.31994/rvs.v9i2.409

\author{
João Paulo Nascimento da Silva ${ }^{1}$ \\ João Luis Souza ${ }^{2}$ \\ Luiz Guilherme Rodrigues Antunes ${ }^{3}$ \\ Daniela Meirelles Andrade ${ }^{4}$
}

\section{RESUMO}

As incubadoras de empresas são instituições que promovem o desenvolvimento local e startups, pois fomentam ações voltadas à criação de soluções inovadoras e empreendedoras. No entanto, para que isso ocorra é necessário que estas instituições tenham boa atuação, e para que isso aconteça recorre-se aos fatores críticos de sucesso. Nesse sentido, o artigo objetiva analisar os fatores críticos de sucesso, propostos por Smilor (1987), de uma incubadora de base tecnológica do Sul de Minas Gerais (Inbatec). Para tanto, adotou-se um estudo qualitativo, descritivo e como procedimento o estudo de caso, a fim de compreender de forma detalhada os processos realizados nessa instituição. Assim, entrevistou-se três sujeitos, sendo um deles da própria incubadora e os outros dois de uma empresa que participou do

\footnotetext{
${ }^{1}$ Mestrando em Administração pela Universidade Federal de Lavras - UFLA, Mestre em Marketing Relacional pelo Instituto Politécnico de Leiria - IPL/PT, E-mail: jpnsilvas@gmail.com, http://orcid.org/0000-0002-3956-823X

2 Mestrando em Administração pela Universidade Federal de Lavras - UFLA, E-mail: joaoluisds@gmail.com, https://orcid.org/0000-0003-1581-0316

Mestre em Administração pela Universidade Federal de Lavras - UFLA, E-mail: luguiantunes@yahoo.com.br, https://orcid.org/0000-0003-2997-2949

4 Professora Doutora da Universidade Federal de Lavras - UFLA, E-mail: daniela.andrade@dae.ufla.br, https://orcid.org/0000-0001-7893-4629
} 


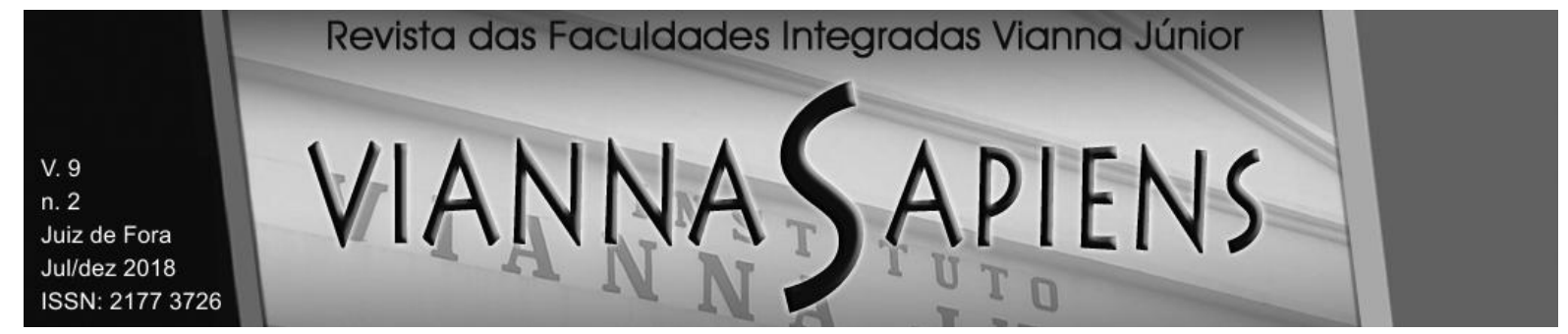

processo de incubação. Como principais resultados têm-se que, dentre dos dez fatores críticos proposto por Smilor (1987), somente três deles são realizados com efetividade pela Inbatec, que são: apoio financeiro em espécie, educação empresarial e vínculos a uma universidade. Entretanto, os demais fatores críticos são parcialmente realizados, o que pode ser justificado pela incipiência da instituição.

PALAVRAS-CHAVE: INCUBADORA DE EMPRESAS. STARTUP. FATORES CRÍTICOS DE SUCESSO.

\title{
CRITICAL SUCCESS FACTORS: A CASE STUDY IN THE INCUBATOR OF TECHNOLOGY-BASED COMPANIES OF A FEDERAL UNIVERSITY OF THE SOUTH OF MINAS GERAIS
}

\begin{abstract}
Business incubators are institutions that promote local development and startups, as they foster actions aimed at creating innovative and entrepreneurial solutions. However, for this to occur it is necessary that these institutions have a good performance, and for that to happen it is used the critical factors of success. In this sense, the present article aims to analyze the critical success factors, proposed by Smilor (1987), of a technology-based incubator in the South of Minas Gerais (Inbatec). For that, a qualitative, descriptive study was adopted and as a case study procedure, in order to understand in detail the processes performed in this institution. Thus, three subjects were interviewed, one being from the incubator itself and the other two from a company that participated in the incubation process. The main results show that of the ten critical factors proposed by Smilor (1987), only three of them are effectively carried out by Inbatec, which are: financial support in kind,
\end{abstract}




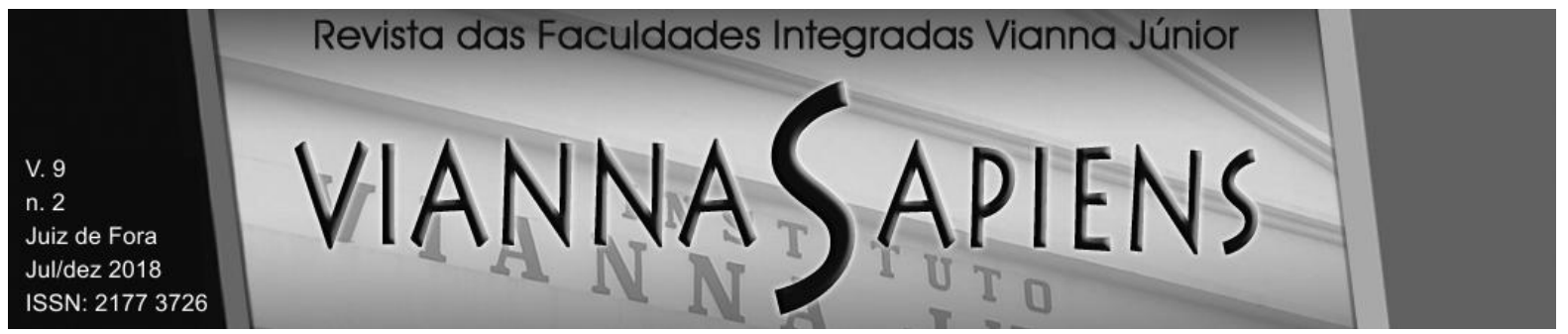

business education and links to a university. However, the other critical factors are partially fulfilled, which may be justified by the incipience of the institution.

KEYWORDS: BUSINESS INCUBATOR. STARTUP. CRITICAL SUCCESS FACTORS.

\section{INTRODUÇÃO}

Já é reconhecido pela literatura organizacional que o ambiente, após a década de 1970, tem passado por constantes mudanças econômicas (ANTUNES, SOUZA, MINEIRO, DE PAULA, SUGANO, 2017). Assim sendo, esse ambiente mutável e altamente competitivo tem afetado as micro e pequenas empresas (MPEs), principalmente àquelas dotadas de tecnologia (startups).

Tais organizações são importantes no cenário nacional (MANSANO, PEREIRA, 2015), pois tem participação expressiva na ocupação e geração de empregos (SANTOS, KREIN, CALIXTRE, 2012). Entretanto, também já é reconhecido que, no início de suas trajetórias, as startups falham por motivos de falta de capital, escassas de habilidades gerenciais, desconhecimento de mercado e demandas inconsistentes (LEWIS, 2001; ZIMMERMANN, CARIO, RAUEN, 2009). Ademais, em especial, também sofrem por causa da sua pequenez, novidade, ilegitimidade, necessidade de altos investimentos e por seus fundadores ainda serem pesquisadores e não gestores (STOKAN, THOMPSON, MAHU, 2015; ANDINO, FRACASSO, 2005).

Desse modo, observa-se que deixar as startups se desenvolverem numa dinâmica natural de mercado pode levá-las a encerrar suas atividades precocemente. Assim, governos de todo o mundo passaram a reunir esforços para fomentar a criação e o desenvolvimento dessas empresas (LEFEBVRE et al., 2014). Diversas ferramentas foram desenvolvidas, e um novo enfoque foi atribuído aos esforços coletivos para sustentação das MPEs (LEFEBVRE et al., 2014), o que 


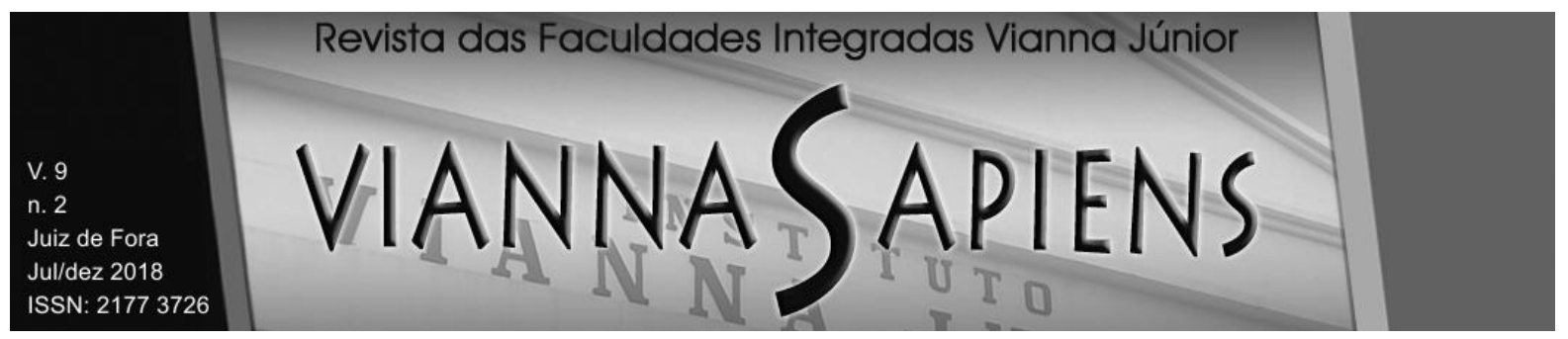

resultou na criação e disseminação das incubadoras de empresas (STOKAN, THOMPSON, MAHU, 2015).

De tal modo, as incubadoras são instituições que apresentam ambientes propícios à criação, crescimento de negócios e soluções inovadoras no mercado, sendo consideradas importantes ferramentas que impulsionam o desenvolvimento econômico, tecnológico e social (Associação Nacional de Entidades Promotoras de Empreendimentos Inovadores [ANPROTEC], 2016). Nesse sentido, as incubadoras objetivam oferecer infraestrutura, suporte gerencial e rede de empresas, de forma a orientar os empreendedores quanto à gestão do negócio e a competitividade no mercado, entre outras questões essenciais ao desenvolvimento de uma empresa (ANPROTEC, 2016; BRUNEEL, RATINHO, CLARYSSE, GROEN, 2012).

As incubadoras assumem um importante papel no desenvolvimento econômico, participando diretamente na formação de empresas (DORNELAS, 2002). Por isto, as incubadoras constituem-se ambiente de fomento ao empreendedorismo e à inovação. Para que as incubadoras tenham uma boa atuação, é necessário observar diversos aspectos como os fatores críticos de sucesso. Nesse sentido, Smilor (1987) apresenta dez fatores críticos que podem contribuir para o desenvolvimento das mesmas. A construção do autor atua desde os processos de regulamentação da incubadora, como também na estrutura física da instituição e na sua equipe de auxílio. Em outras palavras, trata-se de um modelo teórico que pode auxiliar na identificação de melhorias nos processos e lacunas existentes dentro da instituição.

Dessa forma, emerge o seguinte questionamento: Com o modelo teórico proposto por Smilor (1987) é possível analisar uma incubadora de empresas? Assim, o artigo objetivou analisar os fatores críticos de sucesso, propostos por Smilor (1987), de uma incubadora de base tecnológica do Sul de Minas Gerais (Inbatec).

Justifica-se tal trabalho, uma vez que esse tipo de organização tem relevância tanto para o contexto nacional, por auxiliar no desenvolvimento da inovação e estimular o empreendedorismo (ETZKOWITZ, MELLO, ALMEIDA, 2005), como também no contexto regional por trazer impactos positivos a comunidade através da 


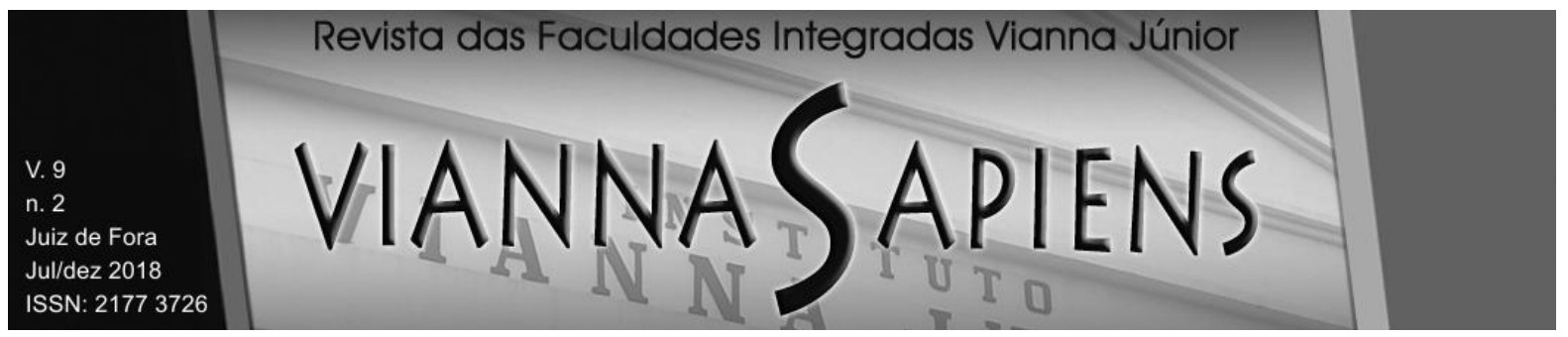

criação de postos de trabalho e ajudando na sobrevivência e crescimento dos negócios (SHERMAN, CHAPPELL, 1998). Por último argumenta-se que esse tipo de pesquisa avança nos estudos acadêmicos sobre a efetividade das incubadoras de empresas, o qual ainda não se encontra consolidada na literatura da área (ANDINO, FRACASSO, 2005).

Essa pesquisa apresenta a seguir o referencial teórico que apresenta o conceito de incubadoras e sustenta os princípios dos fatores críticos de sucesso para as mesmas. Posteriormente detalha-se a metodologia utilizada e apresenta os resultados da pesquisa. Finalmente a conclusão traz os principais resultados encontrados neste estudo.

\section{INCUBADORAS DE EMPRESAS E FATORES CRÍTICOS DE SUCESSO}

O empreendedorismo se manifesta como elemento essencial para 0 desenvolvimento econômico, seja local, regional ou nacional, ao propor novos modelos de negócio, além de contribuir para a geração de empregos e melhoria na distribuição de renda (MARCHESAN, 2016). Luz, Kovaleski, Reis, Andrade Junior e Zammar (2012) comentam que para uma atividade empreendedora desenvolver-se em determinada localidade é necessário que existam oportunidades de mercado e que os indivíduos tenham a capacidade de empreender. Assim, cabe ao setor púbico propiciar ambientes no qual o desenvolvimento de ações empreendedoras incentive a inovação (LUZ et al., 2012), por meio do estímulo e criação das incubadoras de empresas.

Para Dornelas (2001), a incubadora deve oferecer suporte às iniciativas empreendedoras, por meio de assessoria em gestão, suporte às ações mercadológicas e infraestrutura de qualidade, além de possibilitar um passaporte para o mercado exterior, na forma de contato com empresas âncoras e capitalistas interessados em investir em novas empresas. Dessa forma, incubadoras têm como objetivo estimular a criação de novos negócios, amparar o desenvolvimento da 


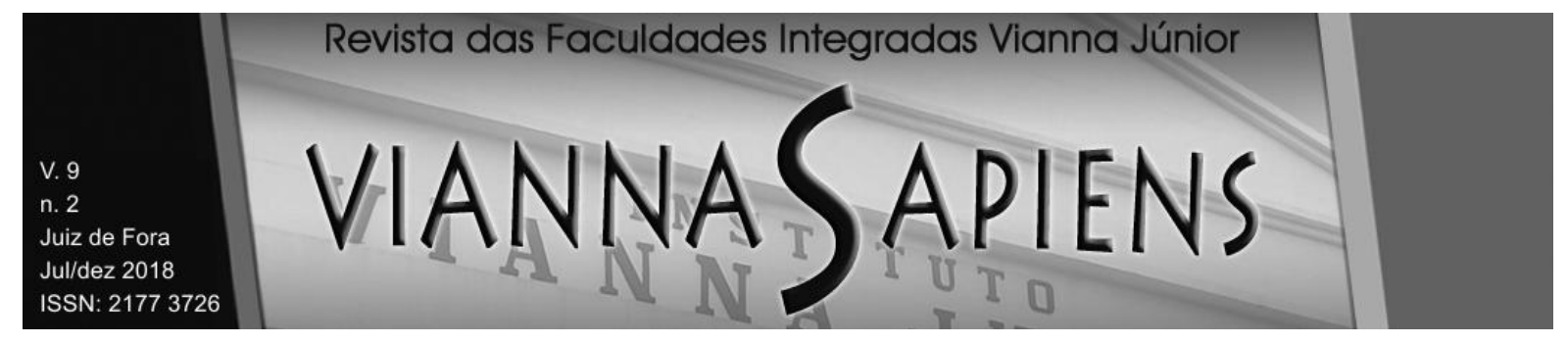

capacidade inovativa de PMEs e difundir a cultura do empreendedorismo, voltado ao conhecimento e à inovação (WONGLIMPIYARAT, 2014), visto que é um dos mecanismos mais eficazes para desenvolvimento de empreendimentos (ARAÚJO, ANJOS, TONHOLO, UCHÔA, 2014).

Para Etzkowitz (2002) e Etzkowitz, Mello e Almeida (2005), a incubadora pode surgir como resultado das relações com a Universidade e Governo, compondo a Tríplice Hélice, de modo a desenvolver um habitat de estímulo, transferência e criação da inovação no âmbito organizacional e tecnológico, de modo a gerar inovação em uma constante construção da realidade econômica.

Para que esse habitat se componha, é necessário entender o funcionamento do negócio da incubadora. Assim, é importante entender que o modelo de negócio desse tipo de organização é composto por processos-chave, como sua gestão e seus fatores críticos de sucesso (ANTUNES et al., 2017).

Ao que se refere ao seu processo de gestão, as atividades das incubadoras se concentram no fornecimento de infraestrutura de qualidade, serviços e apoio gerencial e, mais recentemente, acesso a redes de empresas (BRUNEEL et al., 2012). Fiates et al. (2008) apresentam o conceito de sistema de incubação como um sistema mais abrangente ao processo de incubação, sendo composto tanto do processo de incubação como dos serviços de apoio as empresas. Assim, a incubadora confere às incubadas uma estrutura com confiabilidade enquanto controla um conjunto de recursos assistenciais (SMILOR, 1987), de forma que proporcionam o acesso a uma rede de contatos, sendo este de grande valor as incubadas (HACKETT, DILTS, 2004). Isso aumenta as chances das empresas de sobreviver no mercado em seus primeiros anos de formação (HACKETT, DILTS, 2004; RAUPP, BEUREN, 2011).

No tocante aos fatores críticos de sucesso, Smilor (1987) considera dez fatores críticos para o sistema de incubação: Conhecimentos comerciais no local, Acesso ao financiamento e capitalização, Apoio financeiro em espécie, Suporte da comunidade, Rede empresarial, Educação empresarial, Percepção de sucesso, 


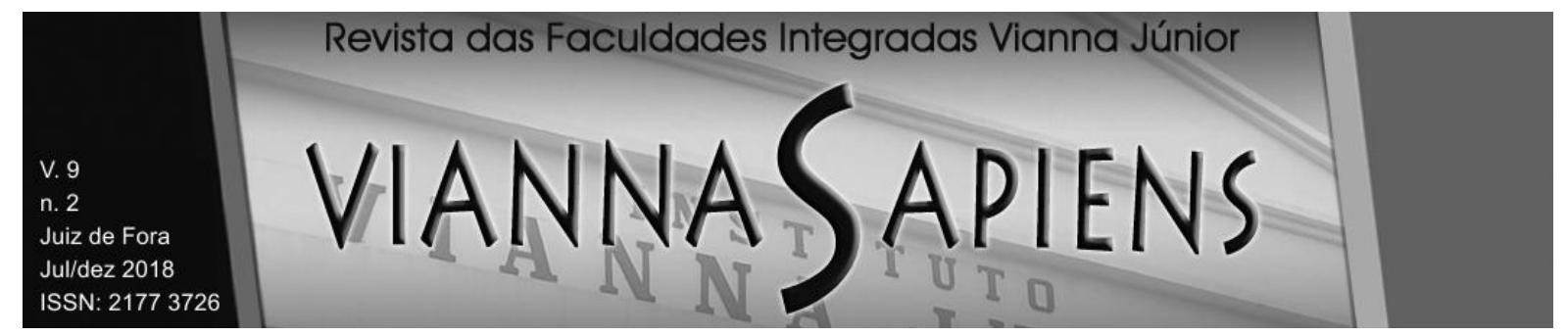

Processo de seleção para inquilinos, Vincular-se a uma universidade, e Marcos concisos do programa com políticas e procedimentos claros.

Os conhecimentos comerciais locais são necessários, pois empresas emergentes demandam por conhecimentos comerciais, know-how para transformar os ativos em negócios viáveis e para responder às mudanças e o crescimento no mercado. Segundo Soetanto e Jack (2003), ao trabalharem na mesma localidade da incubadora, as empresas criam sinergias para melhorar suas capacidades inovadoras e comerciais, podendo haver compartilhamento de recursos, conhecimentos, informações e experiências.

O acesso a financiamento e capitalização apresenta-se como um fator fundamental para as startups, pois é a partir deste que os projetos inovativos podem ser realizados. Segundo Vedovello e Fiqueiredo (2005), um dos objetivos das relações entre incubado e incubadora é o acesso a recursos financeiros e capital de risco que a incubadora pode oferecer através da rede de contatos.

Já o apoio financeiro em espécie trata-se de um tipo de financiamento econômico através do suporte. Estes suportes incluem apoio de secretaria, apoio administrativo, apoio as instalações e assistência a negócios.

A maioria das incubadoras de alguma forma reflete uma necessidade ou diversificação da economia local. Assim, essas instituições necessitam de apoios particulares para solucionar o problema a que se propõe, sendo essa uma caraterística do suporte da comunidade. Segundo Zouain e Torres (2003) as incubadoras que possuem vínculo formal, informal ou que não possuem vínculos com organizações públicas, não são excluídas da necessidade de apoio de recursos públicos e a participação do governo se torna cada mais essencial para o desenvolvimento do movimento e das relações das incubadoras e incubadas.

Quanto a rede empresarial, Smilor (1987) apresenta que o empreendedorismo requer vínculos entre indivíduos e instituições. Para o autor, quanto mais forte, mais complexa e mais diversificada for a rede de relacionamentos, mais o empreendedor terá acesso a oportunidades, a resolução de problemas e maior chance de sucesso para o empreendimento. Segundo Bruneel et al. (2012), acesso a redes facilita a aquisição 


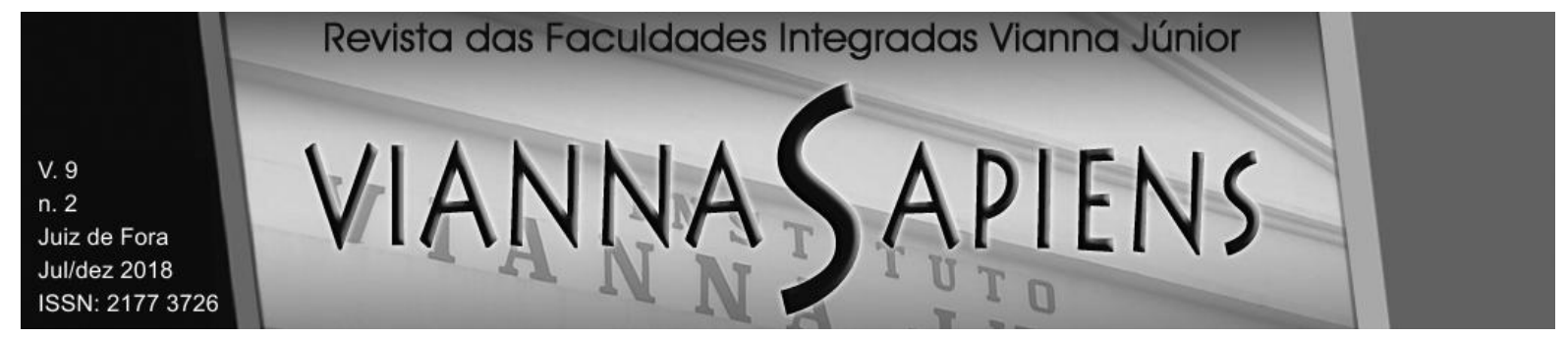

de recursos e de conhecimentos especializados, oferece oportunidades de aprendizagem e permitem que novas empresas construam sua legitimidade mais rapidamente, perante o mercado. Hansen, Chesbrough, Nohria e Sull (2000) apontam ainda sobre o poder que as redes empresariais possuem e que as incubadoras podem utilizá-la para alavancar as empresas incubadas.

A educação empresarial apresenta-se como um importante fator crítico, de forma que, a capacidade de transferir habilidades de apoio de forma contínua entre os empreendimentos da incubadora, o reforço e integração entre os pares, e a capacidade de aproveitar os conhecimentos comerciais em comum se tornam importantes para desenvolvimento de negócios fora da incubadora.

A percepção de sucesso da incubadora ou das instituições a que ela está ligada, pode atrair recursos com maior facilidade, bem como pode atrair empreendimentos mais fortes e ajudar as empresas incubadas a se valorizar no mercado.

Já o processo de seleção de empresas deve avaliar, recomendar e selecionar startups que tenham proximidade com os objetivos da incubadora, podendo incluir capacidade de criar empregos, pagar as despesas operacionais, apresentar um plano de negócios viável, ter rápido potencial de crescimento, e diretamente relacionada à tecnologia. Dessa forma quanto mais clara e desenvolvida o conjunto de critérios de seleção, maior a probabilidade de admitir empresas que possam ser bem-sucedidas.

A vinculação a universidade se mostra mutuamente benéfico para ambas as instituições (universidades e incubadoras), visto que se pode encontrar vantagens como: presença de professores universitários como gerentes ou conselheiros da incubadora; universitários nas empresas incubadas; desenvolvimento de um mecanismo para comercializar pesquisas; desenvolvimento econômico; e desenvolvimento de pesquisas universitárias. Segundo Mian (1996), as relações entre incubadora e universidade promovem o empreendedorismo como forma de atrair e apoiar o desenvolvimento das empresas e promovem a transferência de tecnologia da universidade ao setor produtivo. 


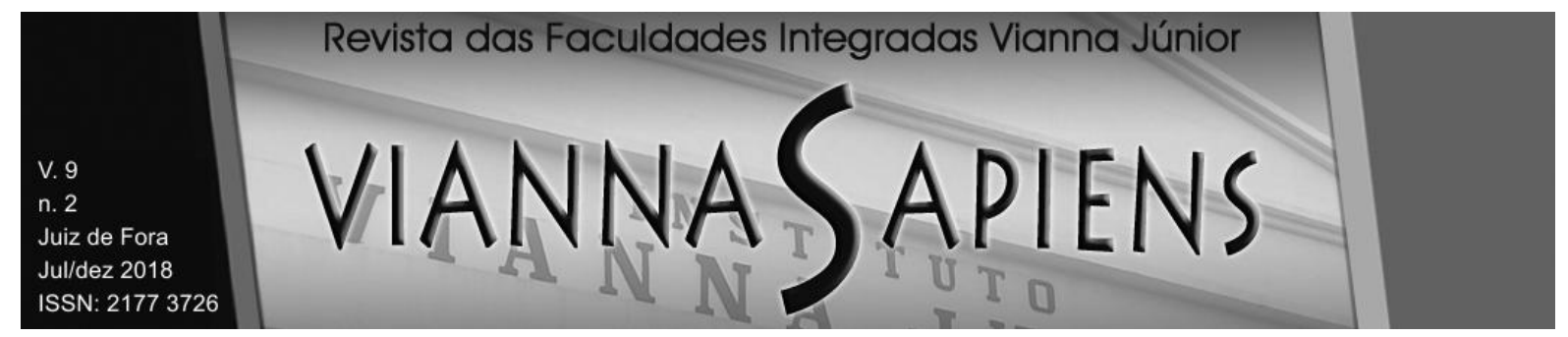

Por fim, têm-se os marcos concisos do programa com políticas e procedimentos claros. Nesse sentido, as empresas inquilinas precisam saber 0 que se espera delas, bem como o que a incubadora as fornecerá, como serão avaliadas e quais serão os procedimentos e as políticas operacionais gerais da incubadora. Dessa forma, a incubadora deve comunicar os marcos do programa, bem como as políticas e procedimentos da incubadora para lidar com o desenvolvimento das empresas incubadas.

Contudo, Smilor (1987) ressalta que nem todas as incubadoras exitosas incorporam, necessariamente, todos esses fatores críticos. No entanto, há correlação direta entre implementação desses fatores críticos e o desenvolvimento bem-sucedido das incubadoras. Assim, quanto mais esses fatores são incorporados na incubadora, maiores são as chances de êxito.

\section{MÉTODOS E PROCEDIMENTOS}

Conforme o objetivo de pesquisa esse estudo se caracteriza de natureza qualitativa, descritiva e com aplicação de um estudo de caso. O estudo de caso pode ser caracterizado como um tipo de análise crítica e profunda de um fenômeno de investigação (YIN, 2001). Assim, os dados foram coletados na Incubadora de Empresas de Base Tecnológica (Inbatec), localizada dentro de uma universidade do Sul de Minas Gerais.

A Inbatec foi criada, em 2009, com base na Lei de Inovação (LEI № 10.973/2004), e considerada um órgão institucional responsável pelo desenvolvimento da cultura empreendedora da universidade o qual está vinculada. Além disso, é incumbida de abrigar empresas cujos produtos, processos ou serviços sejam embasados em resultado de pesquisa aplicada, nas quais a tecnologia representa alto valor agregado. No entanto, somente em 2011, a Inbatec publicou o primeiro edital de chamada pública para seleção de EBTs, tendo nove empresas selecionadas em suas devidas áreas de atuação: agronegócio, biotecnologia, gestão ambiental e tecnologia da 


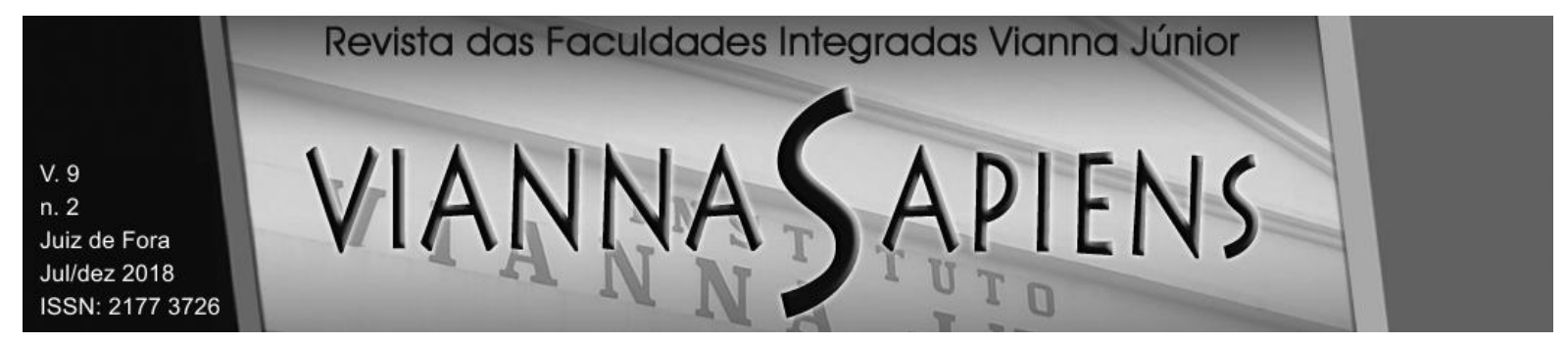

informação. No processe de incubação, as empresas são assistidas em até 36 meses, no qual a incubadora oferece assessorias as empresas incubadas para adquirir maturidade gerencial e alcancar a graduação. Atualmente, a Inbatec mudou sua estrutura administrativa interna e externa, graduou as primeiras empresas e abriu um novo processo de seleção (INBATEC, 2017).

Como levantamento dos dados, utilizou-se de fontes primárias de dados obtidos por meio da entrevista semiestruturada. Assim, na etapa de planejamento da entrevista, construiu-se o roteiro da mesma, considerando os fatores críticos de sucesso de Smilor (1987). Também foram agendadas as entrevistas, conforme a disponibilidade dos entrevistados. Desse modo, entrevistou-se três sujeitos: coordenador da Inbatec, proprietário e gerente de uma das empresas que participaram do processo de incubação. Justifica-se a entrevista com o coordenador da Inbatec, visto que o mesmo participou da incubadora desde a sua fundação. Já o proprietário e o gerente foram escolhidos pela necessidade de se complementar as informações passadas pelo coordenador, a fim de cumprir o objetivo de pesquisa. Tais sujeitos foram escolhidos, uma vez que a empresa dos mesmos foi considerada a mais exitosa do processo de incubação.

$\mathrm{Na}$ etapa execução da entrevista, foi explicado o objetivo da pesquisa, bem como solicitado a permissão para a gravação. As entrevistas duraram em torno de 1,5 horas cada. Após a execução das mesmas, efetuaram-se as transcrições dos relatos dos entrevistados, codificações (E1 - coordenadora da Inbatec, E2 - Sócio da Empresa X, e E3 - Gerente da Empresa X) e análises dos dados.

Como plano de análise de dados, efetuou-se a análise de conteúdo por categorias. A análise temática, ou por categorias, consiste em operações de 'quebra' do texto em unidade (categorias), segundo seus reagrupamentos analógicos (BARDIN, 2016). Assim, procedeu-se três etapas, conforme os pressupostos de Bardin (2016), são elas: pré-análise, exploração do material e tratamento dos resultados obtidos e interpretação.

Na primeira etapa realizou-se a preparação e organização do material, leitura e codificação. Posteriormente, na etapa de exploração, foram localizados os trechos das 


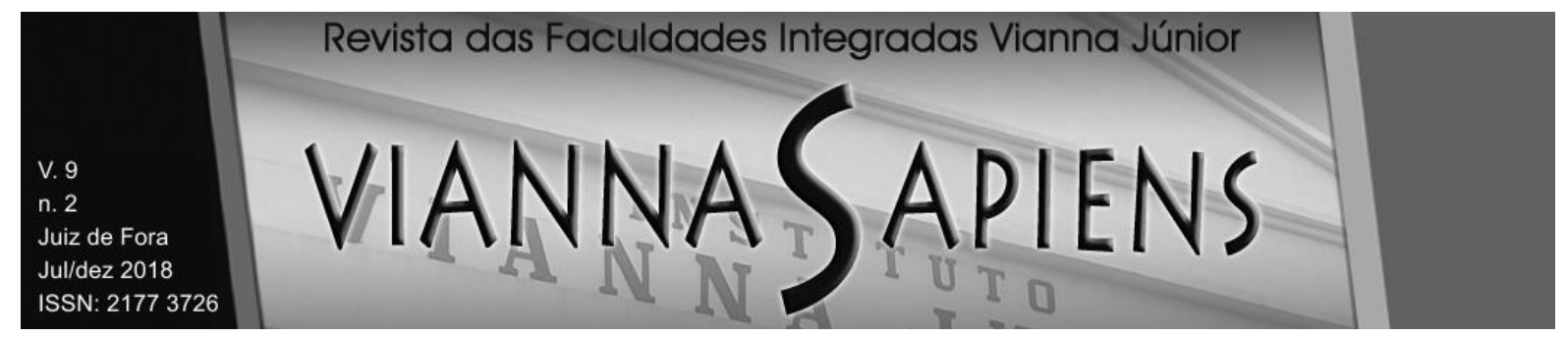

narrativas mais pertinentes e adequados as grades fechadas. Tais grades formaram-se pelas categorias advindas dos dez fatores críticos de sucesso proposto por Smilor. Por fim, foi analisado os trechos buscando confrontá-las com a teoria.

\section{FATORES CRÍTICOS DE SUCESSO NA INBATEC}

Nessa seção serão apresentados e discutidos os dez fatores críticos de sucesso segundo Smilor (1987), aplicados a Inbatec. O autor apresenta o primeiro fator crítico de sucesso das incubadoras como sendo conhecimentos comerciais no local. Conforme o autor, as empresas nascentes apresentam certas dificuldades gerenciais, sobretudo aquelas voltadas a performance eficaz do negócio, bem como voltado ao mercado (marketing). Tal fator se agrava, à medida que se combina as características das próprias tecnologias com a falta de conhecimentos sobre negócios dos proprietários. Tais argumentações são congruentes com os seguintes trechos das entrevistas:

[...] Existe essa dificuldade, de colocar a empresa no mercado, é um grande desafio, acho que é o principal em termos de conseguir vender a tecnologia. Em um primeiro momento, a grande deficiência das empresas é na parte gerencial, e é para isso que elas procuram a incubadora. No segundo momento, que elas já estão, as que conseguem se estruturar melhor, conseguem vencer esse obstáculo da gestão, aí o outro grande obstáculo é o mercado, o comercial, de colocar isso no mercado [...]. [E1]

Todo papel da incubadora tem essa questão de negócios. O que eu reparo lá na incubadora é que a maioria das empresas que estão incubadas lá, elas são empresas estritamente tecnológicas, mas as próprias empresas não têm visão de negócios de mercado. Acredito que das nove empresas, a que teve maior sucesso foi a [Empresa $\mathrm{x}$ ], porque eu também forcei muito essa questão administrativa, por fazer parte do quadro societário. Então, espera-se que a incubadora dê esse suporte na área de gestão, só que foi muito pouco a contribuição da incubador nesse sentido, foi muito baixo. [E2]

O que se observa nos trechos acima é que tanto por parte da incubadora quanto do sócio da Empresa $X$ percebem que a incubadora deve dar o suporte na 


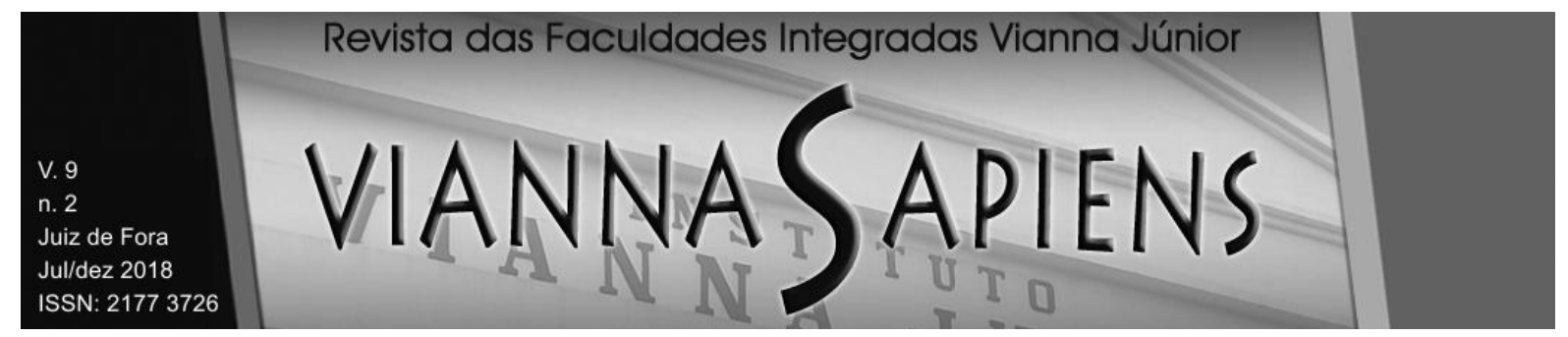

área de negócio e mercado. Tal aspecto é consoante com literatura recorrente, como expostos por Engelman, Fracasso e Brasil (2011), Barbosa e Hoffmann (2013) dentre outros. No entanto, quando considerado a percepção do sócio, a incubadora atuou parcialmente nesse fator crítico de sucesso. Tal aspecto é condizente com o exposto por E3:

Então... no começo era mais uma ajuda estrutural, de espaço do que... na parte técnica, no auxílio administrativo e... dicas administrativas, esse suporte que a incubadora, em tese, tem que dar para essas empresas que estão começando, vamos dizer[...] [E3]

Assim, na percepção da Empresa $X$, os conhecimentos comerciais no local não foram suficientemente desenvolvidos. Ainda, pela fala de E3, a atuação da incubadora deixou a desejar, uma vez que "em tese" as incubadoras deveriam dar esse suporte. Tal aspecto ganha relevância, uma vez que, no momento da entrevista, E3 titubeia ao responder tal ponto. Na pesquisa de Paletta (2008) tal achado se faz convergente, visto que, ao analisar os fatores críticos de sucesso no uso de ferramentas de gestão de empresas incubadas, o autor identificou o uso incipiente de ferramentas que proporcionem o suporte aos gestores das empresas incubadas. O mesmo ainda salienta que as empresas devem se preparar para competir em um cenário global, utilizando instrumentos essenciais para seu crescimento. Dito isso, percebe-se a importância do papel da incubadora.

No fator crítico de acesso a financiamento e capitalização, Smilor (1987) argumenta que as incubadoras são responsáveis, também, por auxiliar na busca de financiamento e capital de risco para as empresas incubadas, uma vez que as incubadas podem não ter experiência. Assim, o acesso a recursos financeiros se torna fundamental para o crescimento dos negócios. Sobre esse aspecto, um dos entrevistados argumentou que:

A Inbatec tentou fazer algumas pontes, chamou por exemplo um investidor anjo uma vez, mas não deu em nada. De vez em quando eles faziam alguns trabalhos com o Sebrae, mas também nada continuado, nada sistemático. [E2] 




Desse modo, o papel da Inbatec sobre o acesso a financiamento e capitalização ainda não se solidificou. Uma possível justificativa para esse aspecto é a incipiência da incubadora e da quantidade de empresas pertencentes a mesma, conforme aponta o responsável pela incubadora:

[...]nós estamos limitados em termos de acesso a investidores, acho que aqui só vai crescer esse negócio de investidores anjo o dia que começar a despontar mais empresas [E1].

Entretanto, mesmo com a limitação apresentado por E1, o mesmo apresenta tentativas para se contornar tal limitação, como segue no seguinte trecho:

Existe uma tentativa, tanto é que agora eu convidei um conselho que é um empreendedor da cidade, que conhece muita gente dessa parte, principalmente de $\mathrm{TI},(.$.$) , e que tem muito interesse em$ termos de investimento nisso, então a proposta é também ver se consegue começar a pensar se as pessoas começam a investir (..) Então existe também uma tentativa conjunta com o [Fulano] para juntar um grupo de pessoas que tem o dinheiro na cidade, porque em Lavras tem pessoas que tem muito dinheiro, para começar a despertar também, talvez, essa questão de injetar algum recurso em termos de empresas. [E1]

Percebe-se, portanto, a iniciativa da incubadora em desenvolver o acesso a financiamentos e capitalização para as empresas incubadas, de modo a desenvolver uma cultura de investimento em startups na cidade. Costa, França e Teixeira (2010) destacam que a capacidade de atrair investimentos está ligada com a gestão eficiente da incubadora, uma vez que a própria incubadora pode se presentar como garantia simbólica de qualidade, pois o nome da instituição contribui com uma imagem positiva às empresas incubadas.

Já no que diz respeito ao apoio financeiro em espécie, esse diferencia-se do fator crítico anterior, uma vez que a própria incubadora financia a incubada através de serviços de apoio (SMILOR, 1987). Esses serviços de apoio podem ser econômicos, como oferecimento de secretariado, instalações, suporte administrativo, acesso a redes e em raras exceções recursos financeiros. Sobre esse fator, os entrevistados da Empresa X expuseram: 


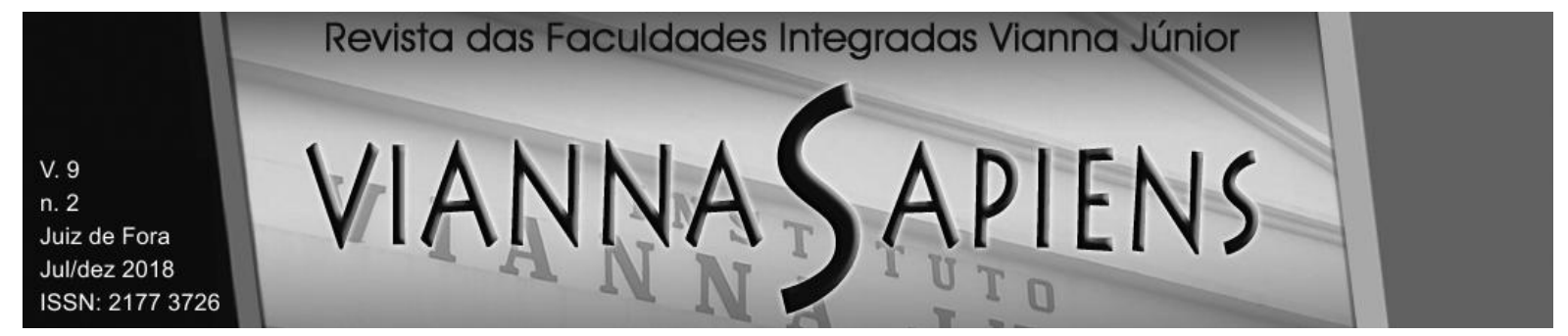

Eles cediam o espaço, cediam a internet que era bem barato, nesse sentido foi bom pra [Empresa X]. A infraestrutura foi muito boa. Mas em termos de gestão, eles emprestavam caminhão para a gente viajar, para fazer exposições, a [universidade] né! no caso. [E2]

Isso, custos, estrutural eh... talvez rede de contatos[...] [E3]

Conforme os trechos acima, a Inbatec dá o suporte de infraestrutura, no qual há o compartilhamento dos custos envolvendo a manutenção da estrutura predial, bem como dos serviços de internet, telefones, recepção, etc. Além disso, há utilização da rede de contatos da incubadora para sanar as demandas das incubadas, como é o caso do caminhão emprestado pela Universidade. Ademais, não se deve esquecer dos auxílios a gestão, embora pouco praticados. Outro ponto importante que deve ser ressaltado, é que a Inbatec proporciona o apoio financeiro, como expõe $\mathrm{E} 1$ :

[...] não tenho dinheiro para pagar bolsa para os outros nem para dar dinheiro para empresa, mas eu posso fazer o contrário, então o que eu fiz, aumentei o preço do aluguel, lá da sala, a taxa de uso, não pode chamar de aluguel, então hoje uma empresa que vai usar uma sala de 40 metros quadrados, no primeiro semestre ela tem desconto de $60 \%$, porque eu não quero pegar esse dinheiro, eu quero que ela use com tecnologia [...] ela tem que começar a cumprir com determinadas atividades, duas atividades são obrigatórias, essas atividades estão todas listadas lá, que é participar de workshop, dar uma palestra, isso pode ser feito dentro das Universidades, dentro de escolas do entorno aqui de Lavras. Então um empreendedor lá vai dar uma palestra, essa palestra dá para ele, por exemplo, 5 pontos, se cada ponto corresponde a 10 reais, então 50 reais, esses 50 reais ele não recebe, ele tem de desconto no próximo semestre, então se ele não fizer nada para o semestre que vem, ele paga a tabela cheia da taxa de uso, mas se ele transferir e, para cada transferência isso tem que ser registrado, assinado e bater foto, ele começa a ter desconto, então esses 600 que ele iria pagar, cai para 300, tiro para $50 \%[\ldots] . "[E 1]$

No fator crítico de suporte da comunidade, Smilor (1987) argumenta que a comunidade desempenha um papel importante para incubadora, seja no esforço em gerar desenvolvimento regional, ou no apoio das instituições públicas e privadas na consolidação das empresas incubadas. Sobre este fator, percebe-se que os 


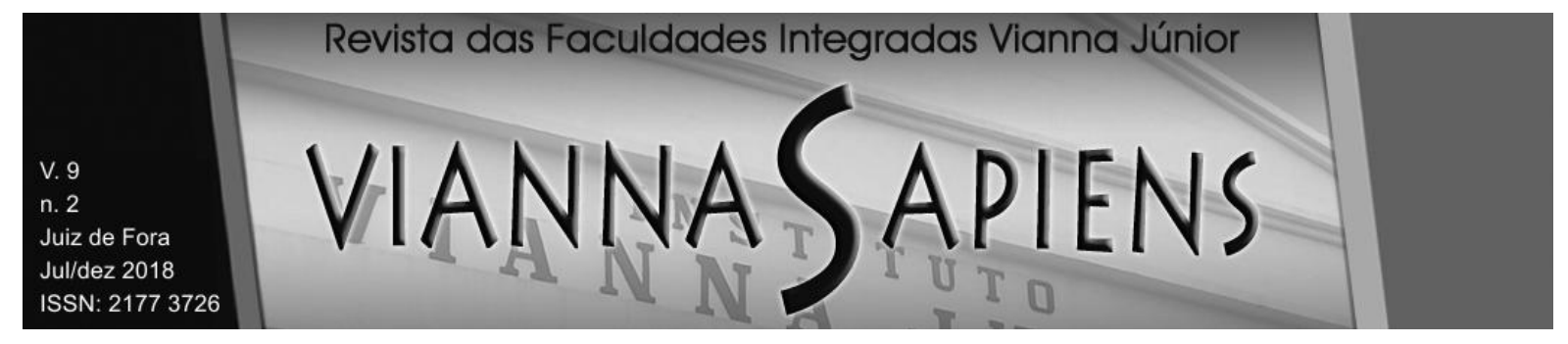

impactos da incubadora na comunidade ainda não podem ser medidos em plenitude, entretanto até o momento houve uma empresa que conseguiu se estabelecer no mercado, que proporcionou a geração de empregos e uma inovação disruptiva no mercado agrícola. Bittencourt, Batista e Souza (2014) identificaram que as incubadoras podem trazer grandes impactos socioeconômicos, proporcionando assim o desenvolvimento local. Os autores comentam que os principais impactos podem ser percebidos no aumento de ações públicas no estímulo da prática empreendedora, mudanças culturais que proporcionaram a criação de novos negócios e o desenvolvimento de instituições de ensino para a formação de pessoas capacitadas. Desta forma, as incubadoras podem promover grandes mudanças, trazendo benefícios a comunidade. Já no que se refere as instituições de apoio, destaca-se os relacionamentos da incubadora com a Universidade mantenedora, SEBRAE, Rede Mineira de Inovação (RMI) e Associação Nacional de Entidades Promotoras de Empreendimentos Inovadores (ANPROTEC).

Ao que se refere a rede empresarial, Smilor (1987) advoga que o empreendedorismo requer um conjunto de ligações entre as mais variadas instituições. Assim, essas ligações possibilitam que o empreendedor tenha maior acesso a oportunidades, chances de resolver problemas e maior sucesso em um novo empreendimento. Desse modo, a Inbatec desenvolve relações com diversas instituições, sobretudo aquelas do suporte da comunidade. Martins, Fiates, Dutra e Venâncio (2014, p. 145), e Hansen et al. (2000) reafirmam a necessidade das empresas incubadas desenvolverem redes de contados com empresas ou instituições, o que possibilita a criação de ambientes que facilitam a "produção, difusão e utilização do conhecimento, a partir do estabelecimento de interações com instituições que de alguma forma contribuem para o aperfeiçoamento do mercado em que as empresas incubadas ou graduadas atuam". Andrade, Pasin, Ottoboni e Mineiro (2016) também retratam os benefícios do desenvolvimento de redes, pois favorecem o processo de implantação e legitimação das incubadoras de base tecnológica. Percebe-se também ações para ampliação dessa rede empresarial, conforme relata E1: 


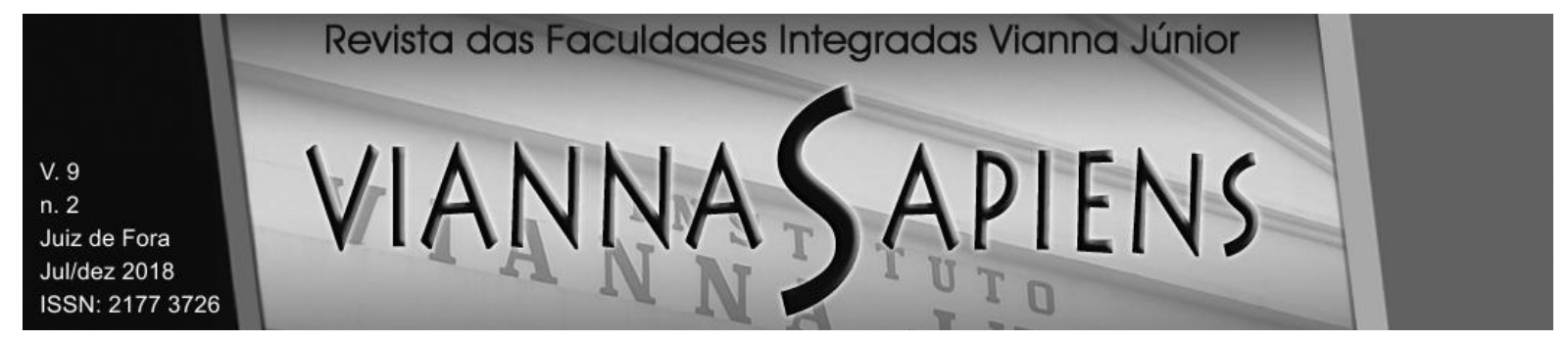

Já até conversei com alguns professores aqui no DAE [Departamento de Administração e Economia], que a proposta é transformar a incubadora em um laboratório do departamento, que é o departamento que tem maior afinidade com a incubadora, não em termos de empresa, mas em termos de necessidade das empresas. [...] justamente para apresentar para todos em termos de discussão que, encima de necessidades das empresas, esse grupo trabalhar até com os alunos da pós-graduação, com as suas expertises, para dar suporte para as incubadas. Que aí eu acho que é um laboratório, que aproxima a empresa do estudante, porque aqui a grande maioria que está aqui, 99,99\% que está aqui dentro do DAE quer ser professor ou trabalhar em alguma outra coisa, e muito porque não tiveram essa aproximação com empresa. [E1]

Sobre o fator crítico de educação empreendedora, Smilor (1987) argumenta que esse fator ajuda a empresa a cortar o "cordão umbilical" com a incubadora, uma vez que prepara o empresário para fazer negócios fora do ambiente de incubação. Assim, se desenvolve habilidades dos empreendedores, por meio de treinamentos e cursos. Sobre a Inbatec, obteve-se:

[No início da incubadora] ela focou bastante na parte de prospecção, as questões de cursos que eram dados, questão de startup weekend, outras startups que tiveram aí, eventos associados com o SEBRAE, então ela focou mais nessa linha de chamar a atenção, principalmente para que o edital tivesse um apelo maior [E1]

Sim, você pode dar um treinamento aqui para empresa, ou duas, três, quatro empresas com o mesmo problema, você junta ali e estudo de caso com professores e alunos da pós-graduação. [E1]

Em ambos os trechos, é possível verificar a atuação da incubadora sobre a disseminação da educação empreendedora. Tais atividades podem ser confirmadas no seguinte trecho:

Ela [Inbatec] nos deu uma ajuda muito forte em questões de propriedade intelectual, que é o registro desta propriedade intelectual $[\ldots] . "$ [E3]

É possível verificar que a Inbatec atua nesse fator crítico, não só propondo a capacitação das empresas incubadas, mas também promovendo a interação entre 


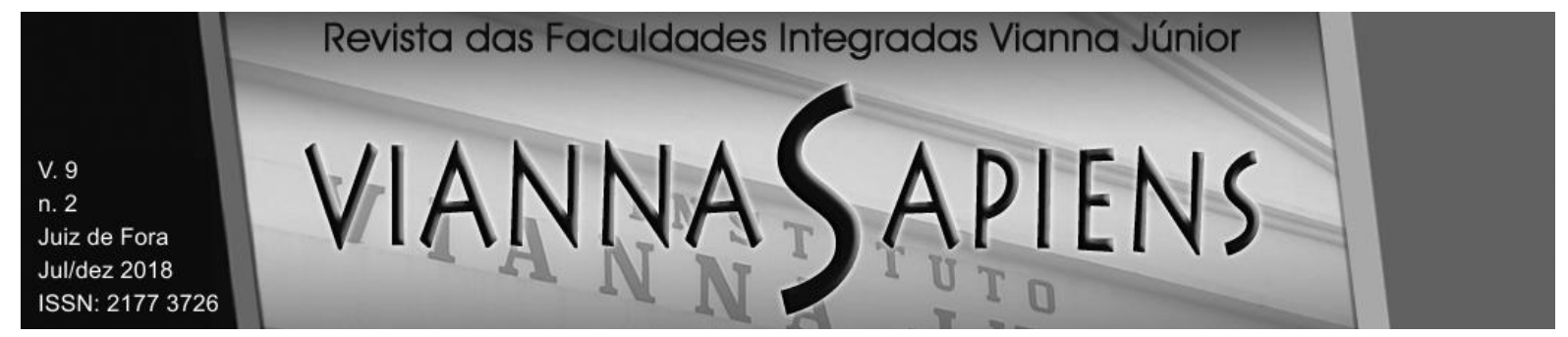

os pares. Esse último também é abordado por Smilor como um aspecto fundamental da educação empreendedora. Bøllingtoft e Ulhøi (2005), Miziara e Carvalho (2008) e Hansen et al. (2000) destacam a relevância de promover a troca de conhecimento entre as empresas incubadas e entre incubadoras, visto que permite gerar sinergias, estimulando o surgimento de novas oportunidades de negócios e promovendo vantagens competitivas. Destaca-se, portanto, o trecho a seguir:

\begin{abstract}
Então agora também no edital, e o projeto/contrato que eles vão firmar agora, eles têm o que eu chamo de Transferência da Vivência Empreendedora, eu não quero saber da sua tecnologia, a tecnologia é sua, não me interessa a tecnologia, eu quero saber o que você tem na sua cabeça quando você resolveu abrir uma empresa, o que você tem feito para mexer com isso, mas eu não quero saber só eu, eu quero que você passe isso para as pessoas, e que não fique só o [coordenador da Incubadora] falando e falando para tudo quanto é lado aí sozinho, eu quero pulverizar isso [...]." [E1].
\end{abstract}

O sétimo fator crítico de sucesso é a percepção de sucesso, e para Smilor (1987) significa que essa percepção pode ajudar a estabelecer a incubadora como um recurso para a sociedade, de modo que ela possa atrair mais recursos para as suas atividades, bem como atrair startups mas fortes e ajudar as empresas a construir sua credibilidade. Assim, quando questionado sobre esse aspecto, obtevese o trecho abaixo mais significantes:

[...] fundos normalmente, eles não fazem o rateio de empreendimentos sozinhos, normalmente eles procuram alguém que, ou uma aceleradora de empresas, incubadora de empresas aonde já tem determinado número de empresas para ele analisar. Esse contato é importante da incubadora para empresa, que é a atração de fundos e visibilidade dá com as empresas lá dentro, com a [Empresa X] lá dentro. Isso foi... fundamental, importante". [E3]

Em outras palavras, a imagem da incubadora auxilia na aproximação de fundos de investimento para com as empresas. No entanto, esse é um dos aspectos para percepção de sucesso. Silva (2017), em sua pesquisa que também buscou identificar fatores críticos, percebeu que os respondentes valorizavam o cultivo de 


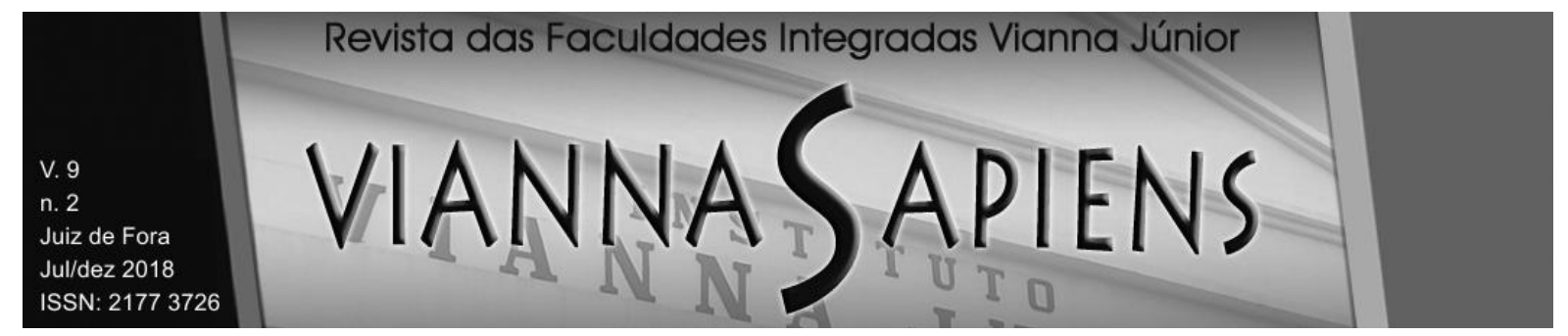

uma imagem que atribuía confiabilidade a incubadora. Segundo a autora, uma boa imagem é fundamental para o desenvolvimento da mesma, pois proporciona 0 surgimento de bons resultados ao atrair mais recursos, além disso, atrai o apoio de instituições da esfera pública e da própria sociedade, despertando assim a atenção de investidores que promovem novos projetos.

Smilor (1987) também apresenta como percepção de sucesso a afiliação da incubadora as principais instituições públicas e privadas (pode-se citar as parcerias da Inbatec com a RMI, ANPROTEC e SEBRAE); surgimento de empresa promissora (no qual houve um caso de sucesso de empresa que estava incubada); e forte conselho consultivo (que contempla os principais órgãos da cidade de Lavras.

O fator de processo de seleção para startups, para Smilor (1987), é um importante aspecto das atividades das incubadoras, no qual, pelo processo de seleção, se avalia, recomenda e seleciona empresas para o processo de incubação. Para o autor, os critérios de seleção devem incluir a capacidade da empresa de criar empregos, pagar suas despesas operacionais, apresentar plano de negócio, apresentar uma oportunidade única, ser uma startup, ser local, ter potencial de crescimento rápido e ser de alta tecnologia. Nesse sentido, os trechos abaixo mencionam que:

Nós lançamos a primeira fase dele agora, no primeiro edital, mês que vem a proposta é já lançar o segundo, então semestralmente, desde que tenha vaga e tenha condição de pegar mais empresas a gente vai pegando." [E1]

E pegando a questão de gestão, pegando a questão de mercado, para criar, muitas empresas que estão entrando lá o conselho optou, o conselho não, depois que o conselho validou, mas teve a banca examinadora para entrada, ela focou mais em termos de equipe e de ideia, e não tanto no desenvolvimento do plano de negócios que eles têm que apresentar, porque senão você ia, praticamente, eliminar quase todas. O pessoal que vem aqui sabe fazer projeto, não plano de negócios para empresa, então foi nessa linha." [E1]

O edital hoje não é para pessoas que tem o vínculo com a Universidade, o edital hoje é para quem quiser, desde que tenha a parte tecnológica envolvida no processo. [E1] 


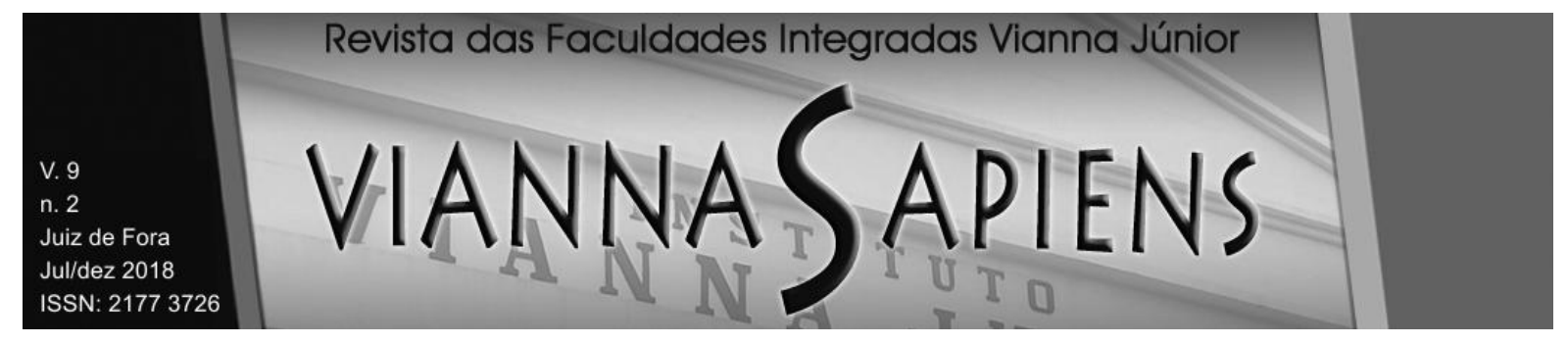

É possível, portanto, verificar uma amplitude do processo de seleção, uma vez que o edital é destinado a toda e qualquer pessoa que queria participar e tenha uma ideia com embasamento tecnológico. Neste sentido, Dornelas (2002) e Lalkaka (2006) salientam a importância de se ter um processo de seleção bem formulado, a fim de evitar futuros problemas no processo de incubação. Além disso, é possível verificar que o enfoque da seleção está voltado para a equipe e a ideia, bem como a saturação das vagas se dá pela infraestrutura. Desse modo, o formato da seleção de inquilinos se pautou nas condições do ambiente o qual a própria incubadora está inserida. Dornelas (2002) comenta sobre os cuidados na abertura dos critérios de seleção, sendo melhor manter algumas instalações vagas do que insistir na incubação de empresas que não se adequem aos objetivos da incubadora

O penúltimo fator crítico denomina-se de vínculos a uma universidade. Segundo Smilor (1987), esses laços são benéficos tanto para a empresa quanto para a universidade. Tais benefícios emergem de diversas possibilidades, como a incubadora instalar-se no campus da universidade, transferência de tecnologia da academia para o setor produtivo, utilização do corpo docente da universidade e dentre outras possibilidades. Assim, no que tange a Inbatec, pode-se verificar:

Essa agora está entrando dez empresas, delas acho que umas sete, então $70 \%$ aí está vinculada a Universidade, umas três estão de pessoas externas, ou que tiveram algum vínculo com a Universidade ou que são externas mesmo. [E1]

No entanto, não só em relação a transformação de pesquisas em empresas, mas a incubadora também se beneficia desse relacionamento. Dessa forma, atualmente a incubadora localiza-se dentro do campus da Universidade, bem como seus funcionários cedidos por esta. Berni, Gomes, Perlin, Kneipp e Frizzo (2015) contribuem nesse sentido analisando a relação entre empresas e a universidade no contexto de uma incubadora de base tecnológica. Os autores encontraram indícios que confirmam os benefícios dessa interação para a universidade, alunos e empresas incubadas. Para a universidade, o principal benefício são as pesquisas que podem ser direcionadas para a solução de questões de interesse social, os 




alunos também se beneficiam através do aprendizado obtido através das pesquisas e das práticas na incubadora e para as empresas incubada a possibilidade de desenvolver novos processos que promovam a distinção no mercado, ou seja, existem benefícios para ambos os lados. Entretanto, os autores também identificaram os processos burocráticos das universidades como dificuldades nessa interação, pois consomem muito tempo, inviabilizando muitas ações.

Por fim, o último fator crítico de sucesso, marcos do programa devem estar concisos com claras políticas e procedimentos, abarca a "química" entre a incubadora e empresas incubadas. Assim, as empresas incubadas devem saber claramente o que a incubadora espera deles, bem como quais são os procedimentos e políticas da funcionamento e avaliação da incubadora. Nesse ponto, E1 argumenta que:

Agora não, tem a proposta de uma aproximação maior em termos de controle das empresas, se ela não estiver ali desenvolvendo o que ela se propôs a fazer ou ter 'pivotado' mas que não esteja desenvolvendo tecnologia, todo semestre tem um conselho e ela pode ser exonerada da incubadora, e aí você tem um novo edital que você pode colocar novas pessoas. [E1]

Tal trecho expõe que para uma empresa continuar no processo de incubação, essa deve estar focado no desenvolvimento e validação de seu projeto/produto. Assim, percebe-se que o desenvolvimento do negócio é um dos critérios estipulados pela incubadora para a boa sinergia entre incubadora e incubada. No entanto, esse aspecto precisa estar mais consistente entre esses atores.

\section{CONSIDERAÇÕES FINAIS}

O presente artigo objetivou analisar os fatores críticos de sucesso, propostos por Smilor (1987), de uma incubadora de base tecnológica do Sul de Minas Gerais (INBATEC). Dessa forma, apresenta-se como resultados que a Inbatec: (i) atende 


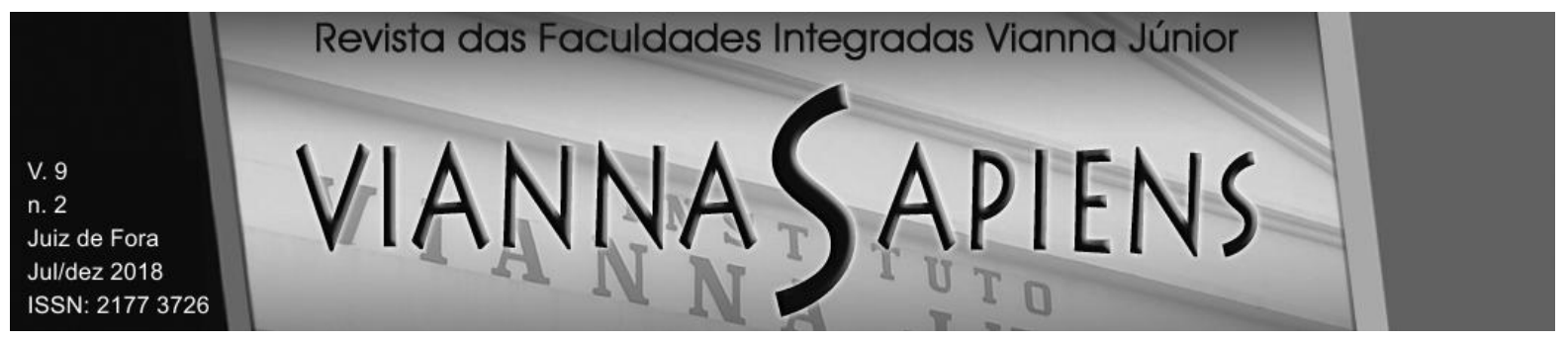

parcialmente os conhecimentos comerciais no local, sendo a atuação do apoio em gestão e mercados incipiente; (ii) não solidificou o acesso a financiamento e capitalização para as empresas; (iii) apoia as empresas incubadas com investimento econômico; (iv) tem baixo contribuição a comunidade local, devido a sua incipiência, mas está afiliada aos principais órgãos da área; (v) ainda desenvolve sua rede empresarial; (vi) realiza a educação empreendedora tanto dentro como fora de suas dependências; (vii) tem na sua imagem aproximação com investidores, mas ainda precisa ser melhor trabalhada. Além disso, apresenta somente um caso de sucesso (empresa entrevistada) enquanto as demais empresas não conseguiram se estabelecer no mercado. E seu conselho apresenta os principais stakeholders da incubadora; (viii) tem um processo de seleção de startup amplo e isso pode levar a problemas de sinergia com a incubadora; (ix) se beneficia e beneficia a universidade o qual está vinculada, mas essa relação já trouxe problemas burocráticos; e $(x)$ ainda precisa estabelecer melhor seus marcos do programa com políticas e procedimentos claros.

Entretanto, cabe destacar que esses resultados devem ser analisados com cautela. Primeiro, por causa da recém atuação da incubadora, visto que, mesmo fundada em 2007, a mesma passou a operar suas atividades somente em 2011, com a primeira chamada de empresas. Tal morosidade se deu por problemas burocráticos com a instituição com a qual a incubadora está afiliada. Assim, entende-se que uma instituição como incubadora necessita de muitos anos para se estabelecer. Nesse sentido, Allen (1988) argumenta que as incubadoras possuem um ciclo de vida, em que na sua primeira etapa, as incubadoras estão no momento em que a comunidade local começa a considerar a criação da incubadora e termina quando a mesma atingiu sua completa ocupação. No segundo estágio a incubadora tem um aumento da frequência de interações do gerente da incubadora com as incubadas e maior apoio é dado pela comunidade local. Por fim, no estágio de maturidade, a incubadora tem mais demanda por espaço do que pode vir a atender, bem como tornou-se centro de referência empreendedora na comunidade. Dessa forma, a Inbatec encontra-se na primeira etapa do ciclo de vida proposto pelo autor. Em segundo, Smilor (1987) também advoga que as incubadoras, não 


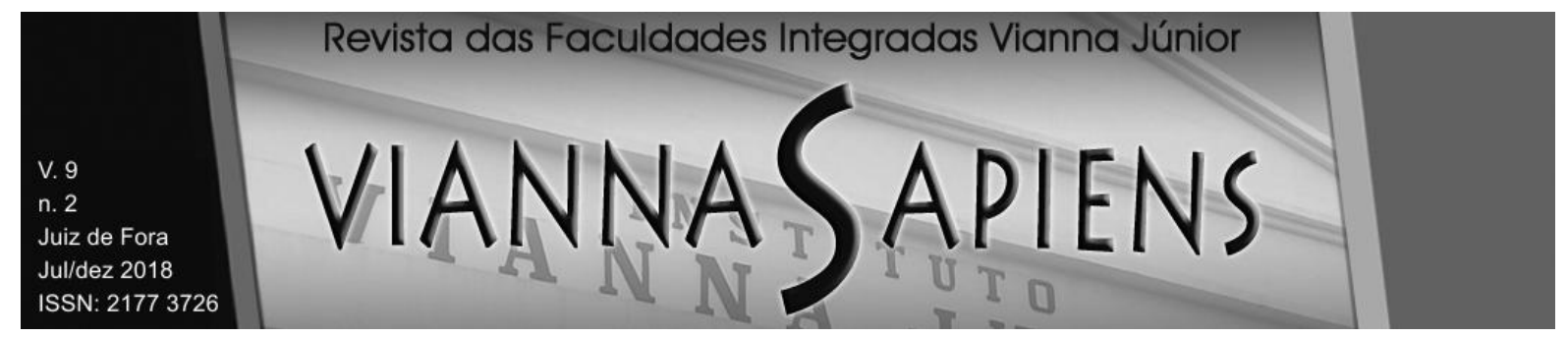

necessariamente, precisam ter todos esses fatores críticos, mas que quanto maior a presença desses, maior as chances de ser uma incubadora exitosa com projetos bem-sucedidos.

Ainda nesse sentido, cabe aqui destacar alguns pontos dos fatores críticos proposto por Smilor (1987). Conforme exposto por Antunes et al. (2017) o negócio da incubadora deve ser considerado a fim de uma melhor gestão da mesma. Assim, aspectos como relação com a entidade mantenedora, recursos financeiros para a própria subsistência da incubadora, gestão dos processos da incubadora, acesso a recursos e outros fatores não foram considerados pelo autor. Entende-se, portanto, que esses aspectos também são críticos para a manutenção e sobrevivência tanto das incubadoras e incubadas.

Como limitação do trabalho tem-se somente a percepção de uma empresa, dentre as nove empresas graduadas. Além disso, o presente estudo contou com a percepção da empresa, que atualmente, está graduada. Dessa forma, seria interessante inserir posteriormente atores (incubadas) que ainda estão no processo de incubação. Como agenda para futuras pesquisas, aponta-se duas propostas. A primeira é reaplicar esse estudo em demais instituições de Minas Gerais, a fim de saber um panorama do Estado. Como segunda proposta, tem-se a atualização dos fatores críticos proposto por Smilor, considerando os outros pontos abordados, visto que o ambiente das incubadoras, bem como sua proposta de valor, alteraram-se conforme as mudanças ambientais.

\section{REFERÊNCIAS}

ALLEN, D. N. Business incubator life cycles. Economic Development Quarterly, 2(1), 19-29, 1988.

ANDINO, B. F., FRACASSO, E. M. Efetividade do processo de Incubação de Empresas. Anais do Encontro Nacional da Associação Nacional de PósGraduação e Pesquisa em Administração, Brasília, 29, 2005. 


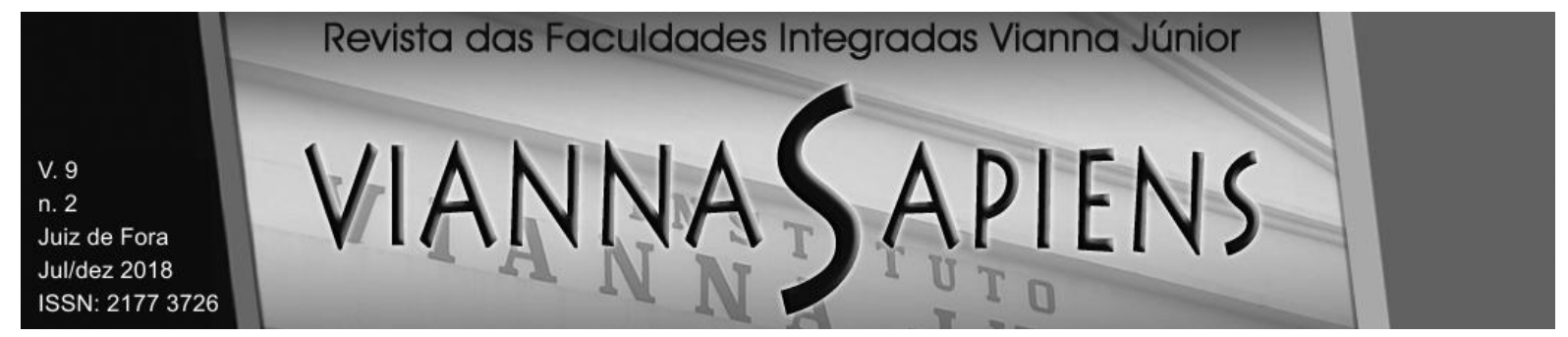

ANDRADE, C. C., PASIN, L. E. V., OTTOBONI, C., MINEIRO, A. A. C. Análise do capital institucional na incubadora de empresas de base tecnológica: um estudo de caso no município de Itajubá-MG. Revista de Administração, Contabilidade e Economia da Fundace, 7(1), 2016.

ANTUNES, L. G. R., SOUZA, T. A., MINEIRO, A. A., DE PAULA, J. S., SUGANO, J. Y. Modelo de Negócio de Incubadoras de Empresas: Revisão de Escopo. Anais do Congresso de Administração, Sociedade e Inovação, Petrópolis, RJ, 10, 2017.

Araújo, V. R. B. S., Anjos, L. C. M., Tonholo, J., Uchôa, S. B. B. Avaliação de Empresas: um estudo em uma empresa incubada no Estado de Alagoas.

Conferência Mundial IASP de Parques Científicos e Tecnológicos e Seminário Nacional de Parques Tecnológicos e Incubadoras de Empresas, Recife. 30, 2014.

Associação Nacional de Entidade Promotoras de Empreendimentos Inovadores [ANPROTEC]. Estudo de impacto econômico: segmento de incubadoras de empresas do Brasil. Brasília: ANPROTEC; SEBRAE, 2016.

BARBOSA, L. G. F., HOFFMANN, V. E. Incubadora de empresas de base tecnológica: percepção dos empresários quanto aos apoios recebidos. RAI Revista de Administração e Inovação, 10(3), 206-229, 2013.

BARDIN, L. Análise de conteúdo. Lisboa: edições, 70, 225, 2016.

BERNI, J. C. A., GOMES, C. M., PERLIN, A. P., KNEIPP, J. M., FRIZZO, K. Interação universidade-empresa para a inovação e a transferência de tecnologia. Revista Gestão Universitária na América Latina-GUAL, 8(2), 2015.

BITTENCOURT, M., BATISTA, G. D. M., SOUZA, E. M. Contribuições de uma incubadora de empresas de base tecnológica para o desenvolvimento socioeconômico de um município médio: a estreita relação entre a INCIT e a cidade de Itajubá/MG. Anais do Seminário Nacional de Parques-Tecnológicos e Incubadoras de Empresas. Belém, 24, 2014. 


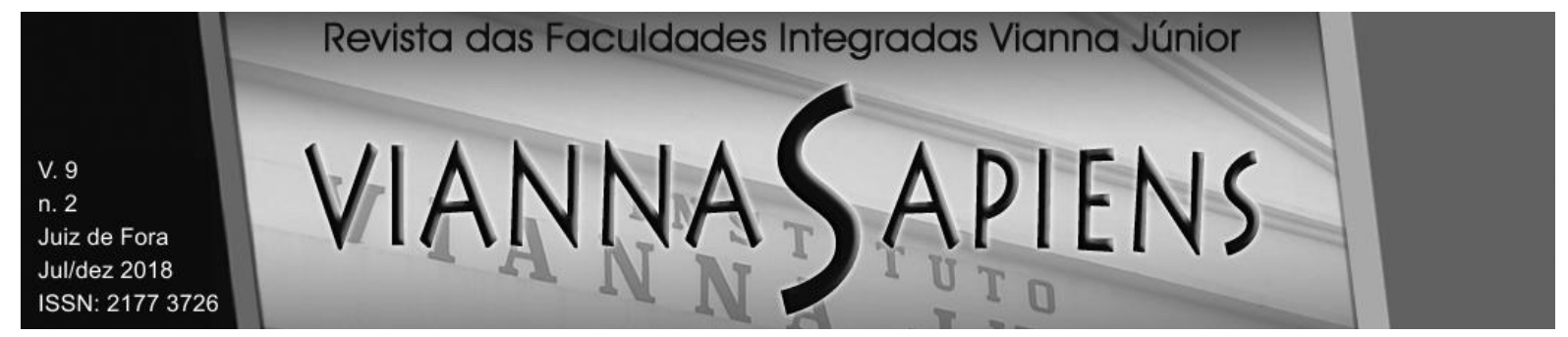

BØLLINGTOFT, A., ULHØI, J. P. The networked business incubator-leveraging entrepreneurial agency?. Journal of business venturing, 20(2), 265-290, 2005.

BRASIL. Decreto-lei № 10.973, DE 2 DE DEZEMBRO DE 2004. Dispõe sobre incentivos à inovação e à pesquisa científica e tecnológica no ambiente produtivo e dá outras providências. Brasília, Art. 2o, X, 2004.

BRUNEEL, J., RATINHO, T., CLARYSSE, B., GROEN, A. The Evolution of Business Incubators: Comparing demand and supply of business incubation services across different incubator generations. Technovation, 32(2), 110-121, 2012.

COSTA, L. F. S., FRANÇA, M. C. F., TEIXEIRA, R. M. Apoio Gerencial na Incubação de Empresas de Base Tecnológica: $O$ Caso da Incubadora Cise. Revista Pensamento Contemporâneo em Administração, 4(1), 2010.

DORNELAS, J. C. A. Planejando incubadoras de empresas: como desenvolver um plano de negócios para incubadoras. Rio de Janeiro: Campus, 2002.

DORNELAS, J. C. A. Empreendedorismo: transformando ideias em negócios. Rio de Janeiro: Campus, 2001.

ENGELMAN, R., FRACASSO, E. M., BRASIL, V. S. A qualidade percebida nos serviços de incubação de empresas. Revista Eletrônica de Administração - REAd, 17(3), 2011.

ETZKOWITZ, H. Incubation of incubators: innovation as a triple helix of universityindustry-government networks. Science and Public Policy, 29(2), 115-128, 2002.

ETZKOWITZ, H., DE MELLO, J. M. C., ALMEIDA, M. Towards "meta-innovation" in Brazil: The evolution of the incubator and the emergence of a triple helix. Research policy, 34(4), 411-424, 2005. 




FIATES, G. G. S., FIATES, J. E. A., CHIERIGUINI, T., UENO, A. T. Um Estudo Analítico de um Sistema de Incubação e uma Proposta para Aperfeiçoamento Orientada a Aumentar o Valor Agregado e ás Taxas de Crescimento dos Empreendedores Incubadors. Anais do Encontro Nacional da Associação Nacional de Pós-Graduação e Pesquisa em Administração, Rio de Janeiro, 32, 2008.

HACKETT, S. M., DILTS, D. M. A systematic review of business incubation research. The Journal of Technology Transfer, 29(1), 55-82, 2004.

HANSEN, M. T., CHESBROUGH, H. W., NOHRIA, N., SULL, D. N. Networked incubators. Harvard business review, 78(5), 74-84, 2000.

INBATEC. (2017). Histórico. Acesso em Ago 15, 2017. Disponível em: <http://www.inbatec.ufla.br/sobre-a-inbatec/historico/>.

LALKAKA, R. Technology business incubators: critical determinants of success. Annals of the New York Academy of Sciences, 798(1), 270-290, 1996.

LEFEBVRE, V. M., RAGGI, M., VIAGGI, D., SIA-LJUNGSTRÖM, C., MINARELLI, F., KÜHNE, B., GELLYNCK, X. SMEs' preference for innovation networks: A choice experimental approach. Creativity and Innovation Management, 23(4), 415-435, 2014.

LEWIS, D, A. Does tecnhology incubator work? A critical review. Review of Economic Development 11, 1-60, 2001.

LUZ, A. A., KOVALESKI, J. L., DOS REIS, D. R., DE ANDRADE JÚNIOR, P. P., ZAMMAR, A. Análise de empresa incubada como habitat de empreendedorismo, inovação e competitividade. Gepros: Gestão da Produção, Operações e Sistemas, 7(4), 43, 2012.

MANSANO, F. H., PEREIRA, M. F. Incubadoras de empresas como mecanismo de apoio ao desenvolvimento econômico. Anais da Conferência ANPROTEC, Cuiabá, MT, 25, 2015. 


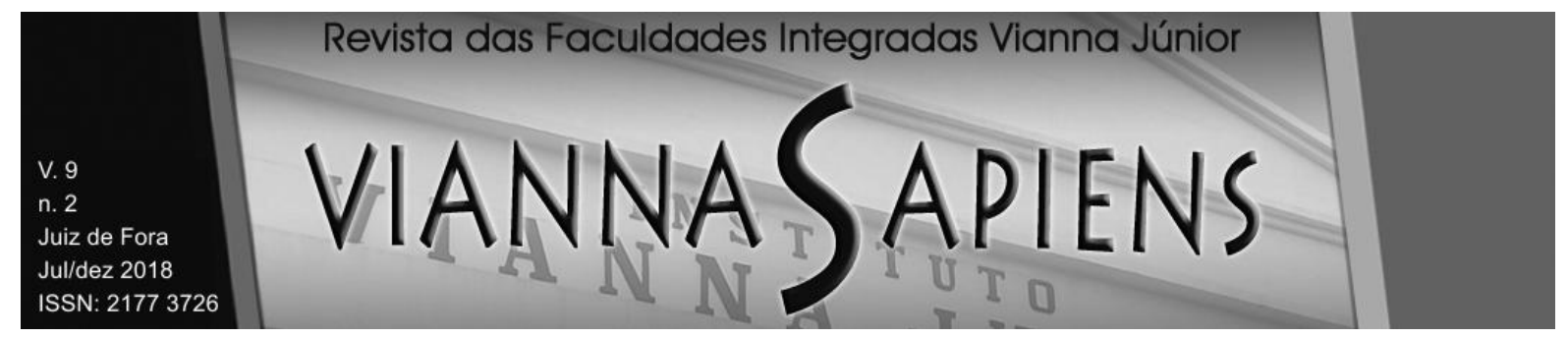

MARCHESAN, A. Desempenho de empresas incubadas, orientação empreendedora e capacidades mercadológicas. Dissertação de Mestrado, Universidade do Contestado, Canoinha, SC, 2016.

MARTINS, C., FIATES, G. G. S., DUTRA, A., VENÂNCIO, D. M. Redes de Interação a partir de Incubadoras de Base Tecnológica: a Colaboração Gerando Inovação. Revista Gestão \& Tecnologia, 14(2), 127-150, 2014.

MIAN, S. A. The university business incubator: a strategy for developing new research/technology-based firms. The Journal of High Technology Management Research, 7(2), 191-208, 1996.

MIZIARA, G. N., DE CARVALHO, M. M. Fatores críticos de sucesso em incubadoras de empresas de software. Revista Produção Online, 8(3), 2008.

PALETTA, F. C. Tecnologia da informação, inovação e empreendedorismo: fatores críticos de sucesso no uso de ferramentas de gestão em empresas incubadas de base tecnológica. Tese de Doutorado. Universidade de São Paulo, 2008.

RAUPP, F. M., Beuren, I. M. Perfil do suporte oferecido pelas incubadoras brasileiras às empresas incubadas. REAd-Revista Eletrônica de Administração, 17(2), 330359, 2011.

SANTOS, A. L., KREIN, J. D., CALIXTRE, A. B. Micro e Pequenas empresas: mercado de trabalho e implicação para o desenvolvimento. (Org.) Rio de Janeiro: IPEA, 2012.

SHERMAN, H., CHAPPELL, D. S. Methodological challenges in evaluating business incubator outcomes. Economic Development Quarterly, 12(4), 313-321, 1998.

SILVA, M. C. Análise do Ecossistema Empreendedor Brasileiro e dos Fatores Críticos de Sucesso para a Gestão de Incubadoras de Empresa. Tese de Doutorado. Universidade Estadual de Campinas, Faculdade de Engenharia Mecânica, Campinas, 2017. 




SMILOR, R. W. Managing the incubator system: critical success factors to accelerate new company development. IEEE transactions on Engineering Management, (3), 146-155, 1987.

SOETANTO, D. P., JACK, S. L. Business incubators and the networks of technologybased firms. The Journal of Technology Transfer, 38(4), 432-453, 2013.

STOKAN, E., THOMPSON, L., MAHU, R. J. Testing the differential effect of business incubators on firm growth. Economic Development Quarterly, 29(4), 317-327, 2015.

VEDOVELLO, C., FIGUEIREDO, P. N. Incubadora de inovação: que nova espécie é essa?. RAE-eletrônica, 4(1), 2005.

WONGLIMPIYARAT, J. Incubator policy to support entrepreneurial development, technology transfer and commercialization. World Journal of Entrepreneurship, Management and Sustainable Development, 10(4), 334-351, 2014.

YIN, R. K. Estudo de Caso: Planejamento e Métodos. Bookman editora, 2001.

ZIMMERMANN, D. M., CARIO, S. A. F., RAUEN, A. Caracterização econômica e dinâmica inovativa das empresas de software em incubadora de base tecnológica em Santa Catarina. Análise - Revista de Administração da PUCRS, 20(1), 2009.

ZOUAIN, D. M., TORRES, L. S. Fatores que influenciam o desempenho de incubadoras tecnológicas no Brasil: estudo de caso sobre três incubadoras localizadas em diferentes regiões do Brasil. Anais do Encontro Nacional da Associação Nacional de Pós-Graduação e Pesquisa em Administração, Atibaia, 30, 2003. 